\title{
The Role of Network Capability and Knowledge Creation in Improving SMEs Business Performance in Indonesia
}

\author{
Heru Sulistyo \\ Universitas Islam Sultan Agung Semarang, Indonesia \\ \{heru@unissula.ac.id\}
}

\begin{abstract}
IKM or Small and Medium Industry (SMI) of fashion is one of the most developed creative industries in Indonesia and is able to make a significant contribution to Indonesia's GDP (Gross Domestic Product). However, the high growth of SMIs has not been able to create a sustainable competitive advantage. Some of the factors that become weaknesses include the low level of knowledge creation and network capability which has an impact on the creation of innovation and business performance of SMEs (Small and Medium Enterprises). This study aims to examine the role of network capability and knowledge creation in increasing innovation and competitive advantage of SMEs. The sample in this study was the SMI creative fashion industry in Jepara and Pekalongan districts as many as 200 respondents. The data collection method used a questionnaire that is distributed to SMI owners. Data analysis was performed using descriptive statistics and structural equation modeling with the AMOS program.
\end{abstract}

Keywords: Knowledge Creation, Network Capability, Innovation Capabilities, Business Performance, Competitive Advantage

\section{Introduction}

Changes in the organizational business environment that are very fast in the current era of globalization have changed the landscape of corporate competition. The rapid development of technology and information, shorter product life cycles and dynamic changes in consumer tastes are some of the factors that drive increasingly fierce competition and determine the existence and competitive advantages of companies today. According to Teece et al (1997), the factors of innovation, technology, dynamic capabilities, product and organizational marketing determine the position of a strong competitive advantage. Consequently, the company must compete on a time basis and be the first to produce new products in the market. Time-based competition is one of the main keys in winning the competition, especially the speed and ability to innovate continuously.

Innovation is a driving force that determines a company's competitive advantage. Innovation occurs as a result of combining new knowledge with existing knowledge to reconfigure organizational capabilities and competencies, resulting in value added products [2]. For many organizations, achieving improved performance and competitive advantage 
depends not only on the successful deployment of tangible assets and natural resources, but also on effective knowledge management. Every company must increase the capability of knowledge assets, both tacit and explicit. The higher the organizational knowledge management, the higher the resulting innovation.

A number of studies that affect the ability of innovation have been carried out by many researchers, including: the importance of organizational knowledge assets [3], [4] intellectual capital [5] knowledge sharing [6], [7] entrepreneurship and knowledge capability [8]. Several studies on the effect of innovation ability on performance and competitive advantage have also been carried out [9] Entrepreneurship, Organization Capability, Strategic Decision Making and Innovation [10]. The current study focuses on developing network capability and knowledge creation in increasing innovation capabilities as well as SMEs' competitive advantage and performance. SMEs make a significant contribution to the national economy in Indonesia. However, in its development, it is still faced with various obstacles in terms of business management, financial management, human resource management and entrepreneurship. Competence and skills and knowledge of human resources are still weak compared to large companies. Human resource practices in many SMEs are often not conducive to knowledge creation and exchange. Generally, SMEs are also involved in less management development activities than larger firms. A number of studies have examined the relationship between knowledge management and performance. However, they focus more on established manufacturing companies. SMEs play an important role in the national economy although there are still some problems and obstacles in the development of SMEs such as management, entrepreneurship, finance, human resources and innovation.

The importance of knowledge creation capabilities is emphasized in the knowledge-based view of organizations, advocated by researchers such as [11], who argue that the two main goals of organizations are the generation and application of knowledge. An organization that has the ability to create knowledge on an ongoing basis has developed dynamic and unique abilities and which have the potential to support ongoing organizational learning. This is supported by the empirical finding that knowledge creation is essential for various organizational processes that support competitive advantage, including new product development and dynamic capability evolution [12].

Network capability, according to [13], is the company's ability to develop and utilize interorganizational relationships to gain access to various resources owned by other actors. Several researchers have indicated that network capabilities are integrated by various dimensions representing different capabilities for managing relationships with other organizations and partners. Similarly, some researchers have observed that networks contribute to the success of small and medium-sized export firms by helping to identify new market opportunities and contribute to knowledge building [14]. From the perspective of Dynamic Ability Theory, network capability is a determining factor for the acceleration of the internationalization of SMEs.

Identified the main skill gaps that hinder innovation in SMEs among others, technical skills, managerial competences [15]. The lack of studies on strengthening knowledge creation in increasing innovation in SMEs is a gap in this research that needs to be identified and tested further. One of the main reasons SMEs invest in knowledge management is to build knowledge capabilities that facilitate effective management and flow of information and knowledge within the company. Good SME's knowledge creation and netwok capability will encourage innovation and performance improvement as well as sustainable competitive advantage. The purpose of this study is to identify and test network capability and knowledge 
creation in increasing innovation capabilities and performance as well as SMEs' competitive advantages. The problem in this research is how to improve the performance of SMEs in creative handicraft and fashion industries so that they are able to have competitiveness in facing MEA 2016.

\section{Literature Review}

\subsection{Network Capability}

Suggest that network capability is the company's ability to develop and utilize interorganizational relationships in order to gain access to various resources owned by other actors. Network orientation is the extent to which a person is willing to depend on social networks in his daily socialization [13]. I argue that people with a high level of network orientation want to maintain norms of dependence, cooperation, and reciprocity because they tend to believe that friends or social connections can secure their survival in an uncertain society. Previous research has shown that people with high network orientation make more use of interpersonal relationships to bridge resource or information gaps between unrelated or outside stakeholders [16]. Once they benefited from their connection, they were expected to return the favor several times over. Networking refers to relational efforts to expand social networks. I suggest that network building includes two main activities: environmental monitoring and affective investment. Entrepreneurs with high networking skills tend to actively seek out information about new partners. In addition, building valid social networks requires people to develop interdependence among networkers by sharing inner feelings and showing personal care through verbal speech or gifts. While network building focuses on expansion, network maintenance requires the ability to ensure stable and long-term exchange relationships with others. People with high network maintenance tend to be considerate and generous. They can understand their friends' feelings and want to listen and help them. In dyadic interactions, they are able to behave and express themselves in a manner consistent with the values and expectations of their peers.

\subsection{Knowledge Creation}

Several studies have found that firms that adopt knowledge management practices perform better than firms that do not. Knowledge management practices have been implemented in various industries including manufacturing, consulting, tourism, and call centers. Knowledge management is divided into six processes, namely knowledge acquisition, knowledge creation, knowledge storage, knowledge distribution, knowledge use and knowledge maintaining. Knowledge management capabilities combine a process perspective that focuses on a series of activities, namely knowledge process capabilities and an infrastructure perspective that focuses on the enabler, namely, knowledge infrastructure capabilities. Knowledge acquisition is the first KM process to emphasize and give special importance to the knowledge capabilities of individuals in organizations. The acquisition of knowledge creation is a process that includes the activities of accessibility, gathering and applying the knowledge acquired. Because knowledge creation is generative, the creation of new knowledge is associated with motivation, intuition, skills and insights that arise in a person. Research conducted by [17]. On small and medium industries in Taiwan concluded that the use of knowledge management has a significant effect on user satisfaction and net benefits. A study conducted by [18] on public 
organizations in Singapore shows that knowledge management capabilities have a significant effect on organizational effectiveness. Research conducted by [19] concluded that knowledge management has a significant effect on innovation and performance.

\subsection{Innovation Capability}

Innovation capability is the implementation and creation of technology that is applied to new systems, policies, programs, products, processes and services in an organization [20]. (Innovation capability is also the ability to absorb and use external information to transfer it into new knowledge. Innovation capabilities are a comprehensive set of organizational characteristics that facilitate and drive innovation strategies [5] .Research conducted by [17] concluded that high innovation capabilities in organizations will improve company performance. The ability to exploit knowledge in obtaining something new or improving it create organizational value or increase the operational efficiency of the organization. Innovation is an important organizational capability because the success of new products is an engine of growth and has an impact on increasing sales, profits, and competitive power for many organizations. Several research findings agree that there is a direct and positive relationship between innovation and performance [21]. Concluded that innovation capability has a significant effect on performance. Innovation capability has been considered as an important factor and intangible asset for companies to create value and sustainable competitive advantage [22].

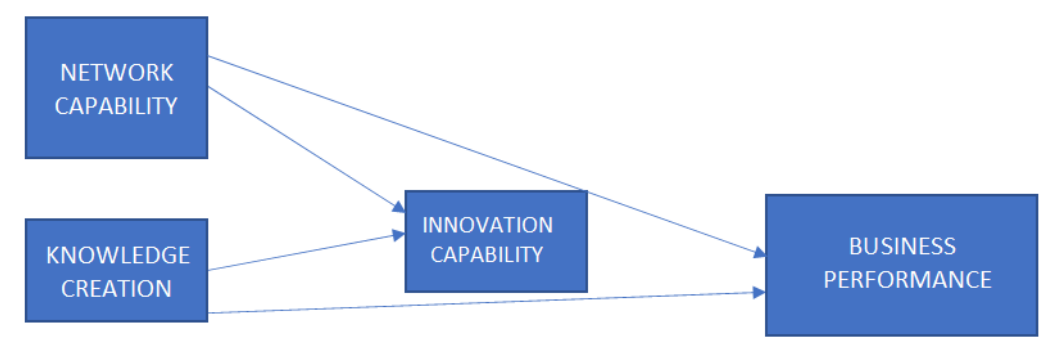

Fig. 1. Conceptual Model

Hypothesis

H1: Network capability has a significant effect on innovation capability

H2: Network capability has a significant effect on business performance

H3: Knowledge creation affects innovation capabilities

H4: Knowledge creation affects business performance

H5: Innovation capability has an effect on business performance

\section{Method}

\subsection{The Sample of Study}

The sample of this study were 184 creative fashion industry SMI players in three districts / cities in Central Java, namely Jepara, Pekalongan, Semarang as many as 184 respondents. Sampling using purposive sampling method based on the consideration of fashion SMEs that have been operating for at least five years and still exist today. 


\subsection{Data Collection Method}

Primary data collection was carried out using questionnaires and interviews. The questionnaire was given to owners / practitioners of the fashion creative industry SMI through the help of surveyors and staff from the SMEs and Cooperative offices in each district / city for 1 month. Furthermore, the results of the questionnaire were validated before processing the data. The need for secondary data was obtained from the Central Statistics Bureau (BPS) of the Central Java Provincial Government (Central Java in numbers, 2017). Secondary data taken is the number of SMI creative fashion industry and their sales turnover.

\subsection{Variable Measurement}

Network capability is measured by 4 indicators: (1) Network is as important as business itself, (2) I am alert to market developments that create potential partnership opportunities, (3) I know well about what others need and try to do what I can for them, and (4) always do what I would like to achieve with others. Knowledge creation is measured by 4 indicators: socialization, combination, internalization and externalization. Innovation capability consists of indicators of product innovation, process innovation, administrative innovation, marketing innovation and service innovation. Business performance is measured by 4 indicators: increase in the number of customers, increase in profit, increase in sales turnover, increase in ROI. All of them are measured using a Likert scale of $1 \mathrm{~s} / \mathrm{d} 7,1=$ strongly disagree and $7=$ strongly agree.

\section{Result and Discussion}

Based on the respondents' responses, the average values and standard deviation are shown in Table 1 below:

\begin{tabular}{|c|c|c|}
\hline Indicators & Mean & Standard Deviation \\
\hline \multicolumn{3}{|l|}{ Knowledge Creation } \\
\hline 1. Socialization & 5.89 & .927 \\
\hline 2. Combination & 5.77 & .925 \\
\hline 3. Internalization & 5.60 & .810 \\
\hline 4. Externalization & 5.33 & .806 \\
\hline Network Capability & & 1.049 \\
\hline 1. Network important as business it self & 5.57 & .868 \\
\hline 2. Create potential partnership opportunities & 5.51 & .889 \\
\hline 3. Try to do what I can for them & 5.58 & .916 \\
\hline $\begin{array}{l}\text { 4. Analyzes what I would like to achieve with } \\
\text { others }\end{array}$ & 5.76 & 1.046 \\
\hline \multicolumn{3}{|l|}{ Innovation Capability } \\
\hline 1. Product innovation & 5.84 & 1.043 \\
\hline 2. Process Innovation & 6.04 & .951 \\
\hline 3. Marketing Innovation & 6.18 & .897 \\
\hline 4. Service Innovation & 6.19 & .831 \\
\hline \multicolumn{3}{|l|}{ Performance } \\
\hline 1. Number of subscribers & 6.19 & .831 \\
\hline 2. Increased profit & 5.86 & .804 \\
\hline
\end{tabular}




\begin{tabular}{llcc}
\hline & Indicators & Mean & Standard Deviation \\
\hline 3. & Sales turnover & 6.02 & .929 \\
4. & Increased ROI & 5.99 & .849 \\
\hline
\end{tabular}

\subsection{PLS Result}

Data analysis uses Smart Partial Least Square (Smart PLS) to estimate the path model using a latent construct with multiple indicators, so that it can help get the latent variable values for prediction purposes. Evaluation in Smart PLS consists of evaluating the outer model (measurement model) and evaluating the inner model (structural model).

\subsection{Indicator of Validity}

The loading factor and $t$ statistical results from the SmartPLS output after removing the factor loading are less than 0.5 . All of the original sample variable knowledge creation values have values above 0.5 and have a statistical $\mathrm{T}$ value $>$ than 1.96 , so it can be concluded that all indicators of knowledge creation are valid. Likewise, 4 indicators of networking capability, 4 indicators of capability and 4 indicators of performance, all have a value above 0.5 and have a statistical $\mathrm{T}$ value $>$ of 1.96 .

Table 2. The Result of Outer Loading

\begin{tabular}{ccccc}
\hline & $\begin{array}{c}\text { Original Sample } \\
\text { Estimate }\end{array}$ & $\begin{array}{c}\text { Mean of } \\
\text { Subsamples }\end{array}$ & $\begin{array}{c}\text { Standard } \\
\text { Deviation }\end{array}$ & $\begin{array}{c}\text { T- } \\
\text { Statistic }\end{array}$ \\
\hline Knowledge Creation & & & & \\
\hline KC1 & 0.772 & 0.754 & 0.120 & 6.433 \\
KC2 & 0.794 & 0.722 & 0.126 & 6.300 \\
KC3 & 0.755 & 0.678 & 0.174 & 4.334 \\
KC4 & 0.709 & 0.696 & 0.136 & 5.211 \\
Network & & & & \\
NC1 & 0.743 & 0.701 & 0.222 & 3.342 \\
NC2 & 0.784 & 0.727 & 0.184 & 4.262 \\
NC3 & 0.825 & 0.798 & 0.093 & 8.866 \\
NC4 & 0.783 & 0.770 & 0.100 & 7.839 \\
Innovation & & & & \\
KI1 & 0.862 & 0.849 & 0.049 & 17.736 \\
KI2 & 0.850 & 0.835 & 0.072 & 11.752 \\
KI3 & 0.805 & 0.781 & 0.085 & 9.435 \\
KI4 & 0.849 & 0.846 & 0.038 & 22.207 \\
Performance & & & & \\
KIN1 & 0.820 & 0.808 & 0.074 & 11.093 \\
KIN2 & 0.795 & 0.781 & 0.101 & 7.852 \\
KIN3 & 0.855 & 0.852 & 0.051 & 16.703 \\
KIN4 & 0.829 & 0.799 & 0.084 & 9.887 \\
\hline
\end{tabular}

All of the original sample variable knowledge creation values have values above 0.5 and have a statistical $\mathrm{T}$ value $>$ than 1.96 , so it can be concluded that all indicators of knowledge creation are valid. Convergent validity of the measurement model with reflexive indicators is assessed based on the correlation between the component score and the construct score calculated by PLS, where individual reflexivity is said to be high if it correlates $>0.5$ with the construct being measured. 


\subsection{Reliability Test}

Composite reliability indicator block that measures a construct can be evaluated with two kinds of measures, namely internal consistency compared to Cronbach alpha, this measure does not assume or equal between measures assuming all indicators are given the same weight. Therefore Cronbach Alpha tends to lower bound estimation reliability, while closer approximation assuming parameter estimation is accurate or reliable. Composite reliability knowledge creation 0.844, network 0.865 , innovation 0.907 and performance 0.895 . All composite reliability scores are above 0.70 , which means they have high reliability. Inner model is a specification of the relationship between latent variables (structural model). This model is also called inner relations, which describes the relationship between latent variables based on the substantive theory of research.

Table 3. The Result of Inner Model

\begin{tabular}{lcccc}
\hline & $\begin{array}{c}\text { Original Sample } \\
\text { Estimate }\end{array}$ & $\begin{array}{c}\text { Mean of } \\
\text { Subsamples }\end{array}$ & $\begin{array}{c}\text { Standard } \\
\text { Deviation }\end{array}$ & $\begin{array}{c}\text { T- } \\
\text { Statistic }\end{array}$ \\
\hline knowledge creation -> inovasi & 0.222 & 0.276 & 0.169 & 1.317 \\
network -> innovation & 0.547 & 0.500 & 0.134 & 4.066 \\
knowledge creation -> performance & 0.219 & 0.151 & 0.154 & 1.424 \\
network -> performance & 0.234 & 0.259 & 0.187 & 1.252 \\
innovation -> performance & 0.351 & 0.352 & 0.158 & 2.230 \\
\hline
\end{tabular}

Table T, $\alpha=5 \%$ and 184 of 1,96 .

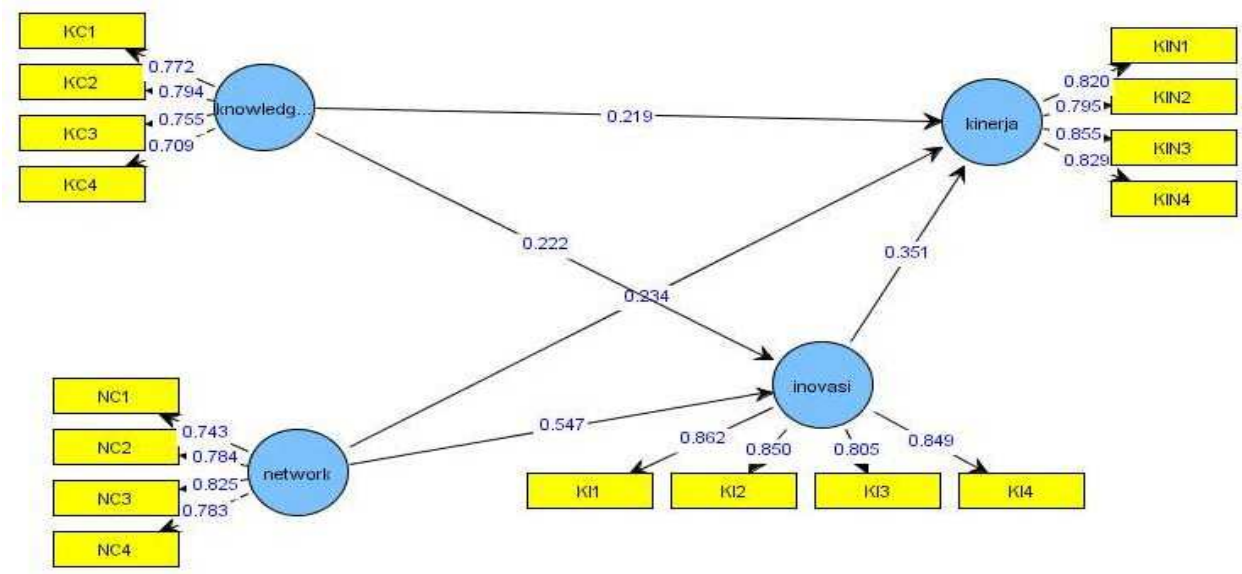

Fig. 2. Relationship between Variables

The effect between knowledge creation and innovation capability is not significant with a $\mathrm{T}$-statistic of $1.317<\mathrm{T}$ table 1.96 , and the original sample estimate value of 0.222 . This shows that the implementation of knowledge creation is not able to produce significant innovations for SME entrepreneurs. Networking capability has a significant effect on innovation capability. This is indicated by the T-statistic value of $4.066<>\mathrm{T}$ table 1.96 , and the original sample estimate value of 0.547 . The higher the SME entrepreneurs create networks with various strategic partners, the more they will generate ideas to produce innovations in both products, processes and new marketing.

Knowledge creation has no significant effect on the performance of SMEs, which is shown 
by the $\mathrm{T}$-statistic score of $1.424<\mathrm{T}$ table 1.96 , and the original sample estimate score of 0.219 . This shows that knowledge creation is not able to increase the performance of SMEs both in terms of sales turnover, profit, ROI and number of customers.

Networking capability has no significant effect on SMEs performance. This is indicated by the T-statistic score of $1.252<\mathrm{T}$ table 1.96, and the original sample estimate score of 0.234 . The ability of SME networking with various strategic partners has not been able to increase sales turnover, profit, ROI and the number of customers.

The innovation capability has a significant effect on the performance of SMEs which is indicated by the T-statistic value of 2,230> T table 1.96, and the original sample estimate value of 0.351 . This shows that the higher the innovation capability will be able to boost the performance of SMEs both in terms of sales turnover, profit, ROI and number of customers.

\section{Conclusion}

The results showed that in order to improve innovation capabilities, SME actors need to develop networks with various strategic partners. For SMEs, by expanding networks with designers, local governments, universities, customer partners from within and outside the country, it will be able to encourage the development of new ideas in product innovation, so that the products sold are unique and in accordance with the trends and tastes of customers.

In addition to customer knowledge management, understanding the dynamic capabilities of marketing is necessary to improve innovation and performance of SMEs. The dynamic capability of SMEs is needed to shape, reshape, configure, and reconfigure company capabilities so that they can respond well to environmental changes and then create innovation as well as performance for SMEs.

\section{References}

[1] Teece, D. J., Pisano, G., \& Shuen, A. (1997). Dynamic capabilities and strategic management. Strategic Management Journal, 18(7), 509-533.

[2] Ahmad Fathi Al-Sa'di, Ayman Bahjat Abdallah, Samer Eid Dahiyat, (2017) "The mediating role of product and process innovations on the relationship between knowledge management and operational performance in manufacturing companies in Jordan", Business Process Management Journal, Vol. 23 Issue: 2, pp.349-376, doi: 10.1108/BPMJ-03-2016-0047

[3] Delgado-verde, M., Mart1, G., \& Navas-lo, E. (2011). Organizational knowledge assets and innovation capability, 12(1), 5-19. https://doi.org/10.1108/14691931111097890

[4] Sulistyo, H., \& Siyamtinah. (2016). Innovation capability of SMEs through entrepreneurship, marketing capability, relational capital and empowerment. Asia Pacific Management Review, 21(4), 196-203. https://doi.org/10.1016/j.apmrv.2016.02.002

[5] Wu, X., \& Sivalogathasan, V. (2013). Intellectual Capital for Innovation Capability: A Conceptual Model for Innovation. International Journal of Trade, Economics and Finance, 4(3), 139-144. https://doi.org/10.7763/IJTEF.2013.V4.274

[6] Kumar, N., \& Che Rose, R. (2012). The impact of knowledge sharing and Islamic work ethic on innovation capability. Cross Cultural Management: An International Journal, 19(2), 142-165. http://doi.org/10.1108/13527601211219847

[7] Lin, H.-F. H.-F. (2007). Knowledge sharing and firm innovation capability: an 
empirical study. International Journal of Manpower, 28(3/4), 315-332. https://doi.org/10.1108/01437720710755272

[8] Kim, Y. J., Song, S., Sambamurthy, V., \& Lee, Y. L. (2012). Entrepreneurship , knowledge integration capability , and firm performance : An empirical study, 10471060. http://doi.org/10.1007/s10796-011-9331-z

[9] Tsai, M.-T., \& Tsai, C. (2010). Innovation Capability and Performance in Taiwanese Science Parks: Exploring the Moderating Effects of Industrial Cluster Fabric. International Journal Of Organizational Innovation, 2(4), 80-103.

[10] Wingwon, B. (2012). Effects of Entrepreneurship, Organization Capability, Strategic Decision Making and Innovation toward the Competitive Advantage of SMEs Enterprises. Journal of Management

[11] Spender, J.-C. (1996), "Making knowledge the basis of a dynamic theory of the firm", Strategic Management Journal, Vol. 17, special issue, Winter, pp. 45-63.

[12] Brockman, B.K. and Morgan, R.M. (2003), "The role of existing knowledge in new product innovativeness and performance', Decision Sciences, Vol. 34 No. 2, pp. $385-$ 419

[13] Walter, A., Auer, M., \& Ritter, T. (2006). The impact of network capabilities and entrepreneurial orientation on university spin-off performance. Journal of Business Venturing, 21(4), 541-567.

[14] Coviello, N. E., \& Joseph, R. M. (2012). Creating major innovations with customers: Insights from small and young technology firms. Journal of Marketing, 76(6), 87-104.

[15] Freel, M. (1999), "Where are the skills gaps in innovative small firms?", International Journal of Entrepreneurial Behaviour \& Research, Vol. 5 No. 3, pp. 144-54.

[16] Su, C., Yang, Z., Zhuang, G., Zhou, N., \& Dou, W. (2009). Interpersonal influence as an alternative channel communication behavior in emerging markets: The case of China. Journal of International Business Studies, 40(4), 668-689.

[17] Wang, M.-H., \& Yang, T.-Y. (2016). Investigating the success of knowledge management: An empirical study of small- and medium-sized enterprises. Asia Pacific Management Review, 21(2), 79-91. http://doi.org/10.1016/j.apmrv.2015.12.003

[18] Pee, L. G., \& Kankanhalli, a. (2016). Interactions among factors influencing knowledge management in public-sector organizations: A resource-based view. Government Information Quarterly, 33(1), 188-199. http://doi.org/10.1016/j.giq.2015.06.002

[19] Darroch, J. (2005). Knowledge management, innovation and firm performance, 9(3), 101- 115. http://doi.org/10.1108/13673270510602809

[20] Lin, R.-J., Chen, R.-H., \& Chiu, K. K.-S. (2010). Customer relationship management and innovation capability: an empirical study. Industrial Management \& Data Systems, 110(1), 111-133. https://doi.org/10.1108/02635571011008434

[21] Thornhill, S. (2006). Knowledge, Innovation and firm performance in high and low technology regimes. Journal of Business Venturing, 21(5), $687 \mathrm{e} 703$.

[22] Panayides, P. (2006). Enhancing innovation capability through relationship management and implications for performance. European Journal of Innovation Management, 9(4), 466- 483. http://doi.org/10.1108/14601060610707876 